\title{
Protegiendo a la montaña, despojando al campesino. Tensiones por el ordenamiento territorial en Viotá (Cundinamarca, Colombia)
}

Protecting the Mountain, Stripping the Peasant. Tensions by Territorial Planning in Viotá (Cundinamarca, Colombia)

Protegendo à montanha, despossando ao camponês. Tensões pelo ordenamento territorial em Viotá (Cundinamarca, Colômbia)

Paula Kamila Guerrero García*

Recibido: 7 de marzo de 2019

Aprobado: 10 de octubre de 2019

Doi: https://www.doi.org/10.12804/revistas.urosario.edu.co/territorios/a.7735

Para citar este artículo:

Guerrero García, P. K. (2020). Protegiendo a la montaña, despojando al campesino. Tensiones por el ordenamiento territorial en Viotá (Cundinamarca, Colombia). Territorios, (42-Especial), 1-24. https://www. doi.org/10.12804/revistas.urosario.edu.co/territorios/a.7735
* Observatorio de Territorios Étnicos y Campesinos, Pontificia Universidad Javeriana, sede Bogotá (Colombia). Correo electrónico:guerrero.paula@ javeriana.edu.co ORCID: 0000-0001-5465-4200 
Palabras clave

Ordenamiento territorial rural, campesinos, conflicto territorial, áreas protegidas, desarrollo rural.

Keywords

Rural territorial planning, peasants, territorial conflict, protected areas, rural development.

Palavras-chave

Ordenamento territorial rural, camponeses, conflito territorial, áreas protegidas, desenvolvimento rural.

\section{territarias 42-Especial}

\section{RESUMEN}

Este artículo aborda el conflicto territorial surgido entre las comunidades campesinas caficultoras de Viotá (Cundinamarca, Colombia) y el Estado a raíz de las decisiones de ordenamiento territorial. En Colombia, el ordenamiento territorial institucional encuentra grandes dificultades de implementación debido al desconocimiento de las formas de vida y de los ordenamientos locales que se dan en el territorio. A través de relatos etnográficos, recorridos y entrevistas con los campesinos, se evidencia cómo el desencuentro entre las formas institucionales de manejo del territorio y las prácticas y sentidos de las comunidades campesinas genera conflictos territoriales que modifican las formas en que los campesinos se relacionan con el espacio habitado, que se tornan en grandes desafíos para su ordenamiento y gestan movimientos organizativos en torno a la gestión autónoma del territorio, su defensa y la de las formas de vida campesinas.

\section{ABSTRACT}

This article addresses the territorial conflict between peasant communities of coffee farmers in Viotá (Cundinamarca, Colombia) and the Colombian state as a result of land management and rural territorial planning decisions. In Colombia, the institutional territorial planning finds great difficulties of implementation due to the ignorance of the forms of life and the local ordinances that occur in it. Through ethnographical stories, tours, and interviews with the peasants, it is evident how the disagreement between the institutional forms of land management and the practices and senses of their communities turn into territorial conflicts that modify the forms in which they relate to the inhabited space, breaking into great challenges for its organization, creating movements around the autonomous management of the territory, its defense and that of peasant life forms.

\section{RESUMO}

Este artigo aborda o conflito territorial surgido entre comunidades camponesas cafeicultoras de Viotá (Cundinamarca, Colômbia) e o Estado em consequências das decisões de ordenamento do território. Na colômbia, o ordenamento territorial institucional encontra grandes dificuldades de implementação devido ao desconhecimento das formas de vida e dos ordenamentos locais que se dão nele. Através de relatos etnográficos, recorridos e entrevistas com os camponeses, se evidência como desencontro entre as formas institucionais de gestão do território e as práticas e sentidos das comunidades camponesas geram conflitos territoriais que modificam as formas em que os camponeses se relacionam com o espaço habitado, tornando-se em grandes desafios para o ordenamento do mesmo e gestando movimentos organizativos em torno à gestão autônoma do território, sua defesa e a das formas de vida camponesas. 
Tenemos la necesidad de defender estos recursos, preservarlos y engrandecerlos, engrandecerlos sembrando más bosques, ojalá que haya más humedales, rescatando los humedales que están a punto de perderse.

Cada vez estamos más convencidos de que tenemos que defender el agua, porque defendiendo el agua se defiende la vida

(Campesino de Palmar Bajo). ${ }^{1}$

Viotá emergió en la segunda mitad del siglo XIX como zona de inversiones agroexportadoras de productos, a partir del asentamiento en un territorio de colonización campesina. Fueron varios los sistemas productivos con los que se experimentó en la zona como el tabaco, la quinina, el algodón y el añil, hasta que el cultivo del café se proyectó como el más rentable y se consolidó en la región. El establecimiento de prósperas haciendas permitió la llegada de nuevos capitales, el mejoramiento del transporte, pero, especialmente, favoreció la atracción de las primeras oleadas de trabajadores provenientes del altiplano. Los mismos que, con el paso del tiempo, entraron en conflicto con el régimen laboral de explotación impuesto por los patronos.

En el siglo XX, este municipio de Cundinamarca fue el nicho de la consolidación de movimientos campesinos de influencia comunista que hicieron de la región un hervidero de debates y conflictos alrededor de temas agrarios. Como resultado, Viotá fue incluida en los primeros experimentos de reforma de la propiedad, se repartieron las grandes haciendas cafeteras entre los campesinos que trabajaban en ellas. Viotá la Roja fue zona de resistencia, surgimiento de ligas campesinas, sindicatos agrarios y bastión de resistencias armadas, estigmatizada después como reducto de las Fuerzas Armadas Revolucionarias de Colombia (FARC) y asiento de destacamentos paramilitares, que vivió momentos dolorosos de violencias comparables a los de la cercana región de Sumapaz.

Más allá de constituir un espacio geográfico delimitado y una fuente de recursos, el territorio es aquí abordado como una construcción histórica y cultural donde tienen lugar las prácticas sociales, políticas y cotidianas. En este sentido, la reconstrucción de la historia agraria de Viotá no constituye simplemente un relato romántico, repetidamente recordado y contado por los campesinos; la memoria del movimiento campesino viotuno es quizás la principal forma de apropiación del territorio por parte de los habitantes de hoy. En tanto proyecto de desarrollo rural, las propuestas del movimiento de la primera mitad del siglo XX estuvieron incompletas en la medida que se centraron en la democratización de la propiedad de la tierra, pero carecieron de un proyecto social para el desarrollo campesino.

Hoy, sus habitantes lo definen como un territorio campesino y lo sueñan con un futuro agrario próspero. Sin embargo,
${ }^{1}$ Este articulo hace parte de la investigación de grado para la Maestría de Desarrollo Rural de la Pontificia Universidad Javeriana titulada: $O r$ denamientos territoriales en tensión. Implicaciones para el desarrollo rural de la subregión de Peñas Blancas, Municipio de Viotá (2016) dirigida por Johana Herrera. Una versión fue presentada en el 56 Congreso de Americanistas en Salamanca, en 2018.

\section{territarias 42-Especial}

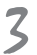


la forma como los campesinos se han relacionado con este territorio ha sido constantemente intervenida por las políticas de desarrollo y de ordenamiento territorial que ha implementado el municipio. Las visiones institucionales del territorio, su manejo y los modelos del ordenamiento mismo no encuentran una correspondencia con aquellas formas de apropiación del espacio rural por parte de las comunidades campesinas, lo cual ha generado diversos choques y desencuentros entre la población y el Estado.

Los desajustes entre las visiones del territorio y su ordenamiento, lejos de ser una particularidad del municipio, como sus luchas por la autonomía y el derecho a la tierra, son una realidad recurrente en los municipios rurales del país. Estas páginas, sin embargo, plantean la necesidad de armonizar dichas visiones a partir del conocimiento profundo del territorio tanto de su contexto histórico, como de sus dinámicas productivas presentes y de las características de quienes lo habitan.

El presente artículo recoge las percepciones de los campesinos caficultores de Viotá, Cundinamarca (Colombia), en torno a la problemática de traslapamiento de sus títulos de propiedad con la zona de reserva. Percepciones que derivan en cuestionamientos en torno al manejo estatal de los territorios locales que ignora las dinámicas históricas y cotidianas que se dan en ellos, que se constituyen en temas fundamentales en las discusiones sobre desarrollo rural. El artículo está dividido en cinco partes. La primera es una aproximación etnográfica a la Cuchilla de Peñas Blancas, territorio en disputa, y a las tensiones en torno a las figuras de ordenamiento. La segunda y tercera parte se concentran en los mecanismos de defensa adoptados por los campesinos frente al acaparamiento de sus territorios. La cuarta recoge una propuesta emergente de desarrollo orientada a la autonomía campesina que surgió en medio de las reflexiones de los afectados. La última parte recoge elementos de una propuesta para armonizar la tensión entre las visiones institucionales y locales, que invita a pensar el ordenamiento como una forma de defensa de la vida campesina.

Esta investigación se nutrió del acompañamiento y la observación realizada durante el curso Reparaciones territoriales para la paz en la vereda El Palmar sector bajo, en adelante Palmar Bajo, en el marco del proyecto Viotá - Poniendo los cimientos para la construcción de paz (2015), que contó con la participación de la Organización de Estados Iberoamericanos, el Instituto Pensar de la Pontifica Universidad Javeriana, la Corporación Vivamos Humanos, la Fundación Nueva Urbe y la Alcaldía de Viotá. La asistencia promedio fue de 25 hombres y mujeres por sesión (4 sesiones), en un rango de edad entre los 30 y 60 años. Todos los participantes se autorreconocieron como campesinos a la vez que manifestaron dedicarse a labores agrícolas, el cultivo de café fue el común denominador. Se 
contó con la participación de miembros de la Junta de Acción Comunal de Palmar y representantes de asociaciones de productores de café y aguacate. Algunos asistentes se reconocieron como víctimas del conflicto armado. Esta información se complementó y profundizó a través de entrevistas semiestructuradas de corte etnográfico con habitantes que se asentaron en la subregión de Peñas Blancas a mediados del siglo pasado y otros nacidos en ella. Se indagó por temas relativos al poblamiento de la vereda, así como a las transformaciones de prácticas productivas que constituyen el territorio. Los relatos de vida dieron pie a la reconstrucción de la historia de la región asociada al territorio. En estas entrevistas también se abordaron otros temas identificados en la revisión bibliográfica y emergentes durante recorridos de reconocimiento y ejercicios de cartografía social.

El ordenamiento territorial institucional encuentra grandes dificultades de implementación debido al desconocimiento de las formas de ordenamiento territorial local que se dan, de facto, en él. Los conflictos territoriales los entenderemos aquí como la forma visible de aquellas tensiones entre los modelos de desarrollo, que derivan en formas institucionales de manejo del territorio y las prácticas y sentidos a partir de los cuales las comunidades campesinas habitan dicho territorio. El desencuentro entre estas visiones en el territorio tiene la capacidad de generar conflictos territoriales mayores que modifican las formas en que los campesinos se han relacionado con el territorio, tornándose en grandes desafíos para el ordenamiento de este.

Los habitantes, campesinos caficultores de la vereda ${ }^{2}$ Palmar Bajo en Viotá en Cundinamarca, en el centro de Colombia (figura 1), identifican una serie de conflictos que guardan relación con la vulnerabilidad ambiental de las coberturas y estructuras ecológicas principales, tales como la deforestación y la pérdida de productividad de los cultivos; otros conflictos se derivan del uso y el manejo de los recursos, relacionados con la contaminación de fuentes hídricas durante la cosecha del café o por desprotección de los nacederos. Sin embargo, el conflicto más relevante de los últimos años surge directamente de la normatividad y regulación sobre el uso del suelo como el caso de la afectación a los títulos de propiedad por cuenta de la figura de reserva forestal. Esta cuestión se constituye en un conflicto territorial de carácter subregional que agrupa las veredas sobre la franja suroriental del municipio y está generando impactos importantes para los habitantes de la parte alta del municipio.

La Cuchilla de Peñas Blancas o de Subia delinea el extremo oriental del municipio y de la provincia del Tequendama y traza el límite natural con la vecina región del Sumapaz. El Plan de Ordenamiento Territorial (РОT) municipal la identifica como un lugar estratégico y la caracteriza de la siguiente manera:
${ }^{2}$ Subdivisión administrativa territorial en zonas rurales en Colombia. 
Figura 1. Paisaje cafetero de Palmar Bajo

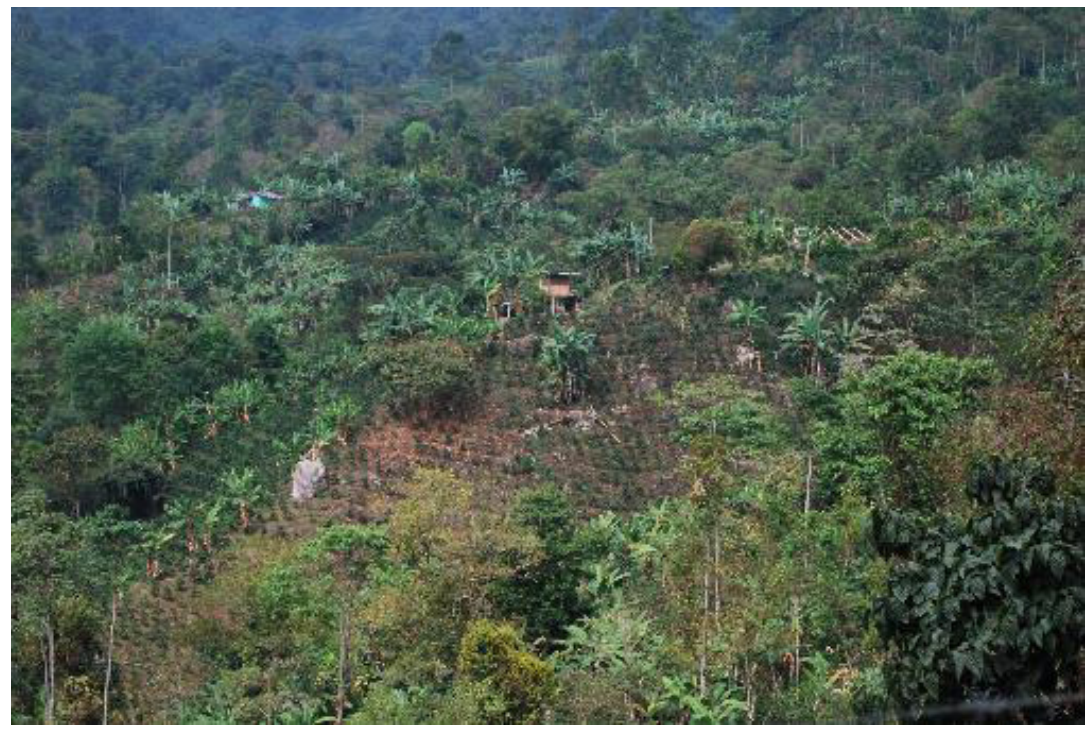

Fuente: Tomada por la autora.

Figura 2. Casa campesina en Palmar Bajo. Peñas Blancas al fondo

tersitarias

42-Especial

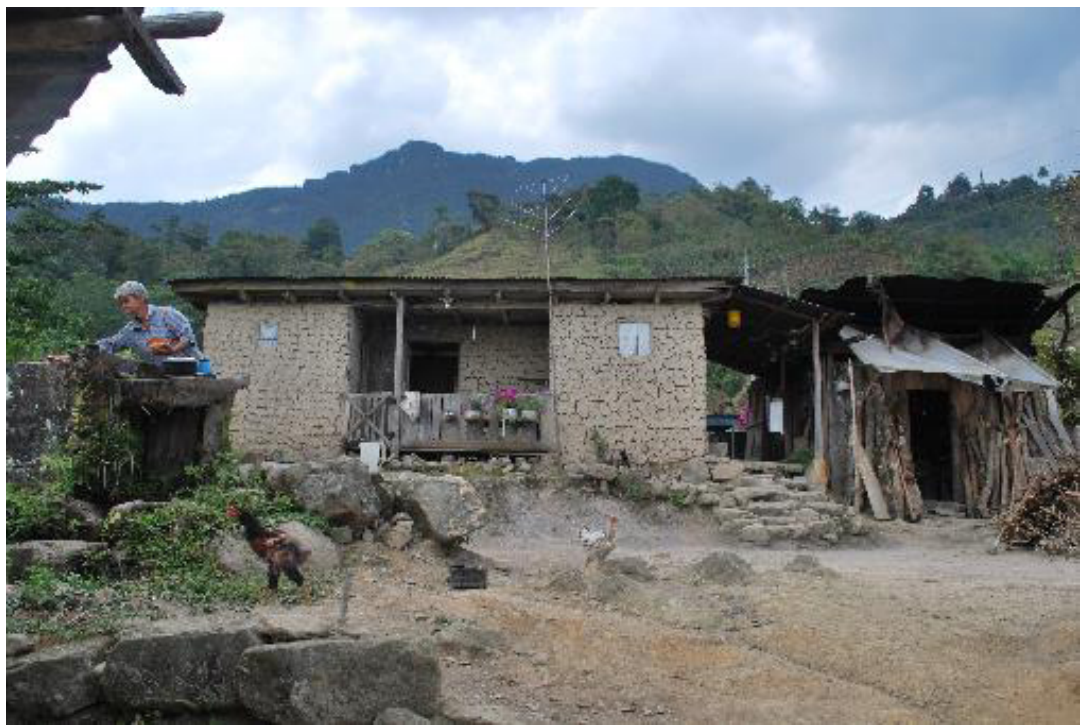

Fuente: Tomada por la autora. 
En ella se encuentran los sitios principales de protección hídrica y paisajística de la región, es un sistema de lugares de interés ecológico, turístico y científico, que se debe interrelacionar a través de caminos adecuados y equipamientos (refugios, puntos de encuentro didácticos y ecológicos) que faciliten recorridos, estancias y miradores, en el cubrimiento de las áreas: El Cerro de la Popa, La laguna del Índio, El Templo, El Alto del Pino, etc. (Alcaldía Municipal de Viotá, 2001, p. 20).

Los habitantes de esta porción del municipio - que en adelante llamaremos subregión de Peñas Blancas- coinciden al identificar La Cuchilla como un lugar de importancia mayúscula. La montaña es un testigo silencioso y cotidiano de su quehacer campesino, entre otras cosas, porque se trata del elemento espacial a partir del cual leen el territorio, su norte: el espacio se entiende en referencia al arriba y abajo de la montaña (figura 2). Asimismo, este lugar guarda una especial relación con los nacimientos de agua que abastecen a la subregión y al municipio. Saben que es una zona de la que dependen sus formas de vida campesina. Durante mi estadía investigativa propusieron realizar recorridos de reconocimiento por el pie de la cuchilla, en dirección a la Laguna del Índio, en Alto Palmar.

Acordamos encontrarnos en "El Descansadero", para empezar desde allí nuestra "Caminata por la defensa del futuro", como nombraron el ejercicio de cartografía social. Desde una altura de 1722 m.s.n.m., 30 personas nos introdujimos en lo que el ordenamiento territorial institucional nombra como un "suelo de protección y de importancia ambiental". Algunos de los asistentes habían participado en proyectos de reforestación de la zona implementados por instituciones estatales hace algunos años, otras no visitaban el lugar desde su infancia. Poco a poco empezaron a volver del recuerdo las historias de ese lugar que en el pasado fue explotado por el aserrío Matallana, según contaron. Estos inhóspitos caminos eran frecuentemente transitados por borrachos que perdían la conciencia a causa del chirrincho, destilado de caña, ya que en otras épocas esta zona específica fue dominada por los sacatines o productores de aguardiente casero. En aquella época, siglo XIX, la comunicación con el pueblo vecino de Silvania era mucho mayor debido el contrabando de licor, de forma que se establecieron caminos por donde los comerciantes transportaban el aguardiente chochuno en totumas.

Nos acercábamos a la Laguna del Índio, un antiguo lugar sagrado de los indígenas panches que "no es una laguna, sino un humedal, un fango peligroso". Este humedal se alimenta de las vertientes que bajan de la cordillera y del agua que captan los árboles cuando llueve y luego se distribuye en las numerosas quebradas que descienden por el territorio. "Dicen los antiguos que esta laguna tiene un encanto, una riqueza..." no en vano hoy territarios 42-Especial 7 
día provee de agua a la zona urbana del municipio. "Yo no venía desde cuando esto era potrero, hará por ahí 35 años. Entonces era fácil pasar, hoy en día no: ha resurgido vida", comentaba un hombre sorprendido. Los cambios que ha tenido la vegetación en las últimas décadas son evidentes, pero no fortuitos, pues la zona dejó de ser ganadera y pasó a convertirse en reserva forestal pública a partir del interés y trabajo de la comunidad, como relató uno de los asistentes:

Hace 30 años, con el primer alcalde de elección popular de Viotá, iniciamos una lucha para recuperar este lugar porque todo esto era ganadería. Allá nos encontrábamos con una señora que vendía quesos por ahí y fue dura la lucha, dura para poderla convencer de que esas tierras debía de venderlas y dejarlas. Unos vendieron un pedazo, después vendieron otros y así se fue formando la reserva forestal... Pedimos unos árboles que se llaman urapanes, que son naturales de esa zona, los sembramos y ahí están. De ahí para acá se ha comprado, se ha extendido la reserva que hoy veo de verdad cada vez más grande (Campesino habitante de Palmar Bajo, 2015).

En la actualidad, estas áreas de protección ambiental han sido definidas para el municipio como reserva forestal protectora, reserva forestal protectora y productora y zonas de recarga de acuíferos o nacimiento de agua (figura 3 ). Debido a las características hidrográficas y meteorológicas que presenta Peñas Blancas, así como a las condiciones de sus suelos y su vegetación, esta área cumple con la función de "preservación, protección, conservación y regulación del sistema hídrico" que garantiza el flujo de agua para la región (Corporación Autónoma Regional, 2004). Bajo este entendimiento se creó el Distrito de Manejo Integrado Peñas Blancas y del Subia en 1994 (Alcaldía Municipal de Viotá, 2012). El área del Distrito de Manejo se ubica en jurisdicción de los municipios de Viotá, San Antonio y El Colegio; comprende 5985 ha., de las cuales la mitad, es decir 3000 ha., pertenece a Viotá (Alcaldía Municipal de Viotá, 2012; Corporación Autónoma Regional, 2004). No está de más decir que la Política de Desarrollo Ambiental del municipio ha estado enfocada en la recuperación y protección de la estructura ecológica principal de influencia rural, por tanto, la Cuchilla de Peñas Blancas ha jugado un papel protagónico en ella (Alcaldía de Viotá, 2001; 2011).

La figura 3 presenta las zonas de uso de acuerdo con el Esquema de Ordenamiento Territorial de Viotá, principal exponente de la visión institucional del ordenamiento. En general, en el municipio se identificaron sistemas de producción que son entendidos como unidades de análisis/gestión que operan bajo una lógica socioeconómica de aprovechamiento de recursos biofísicos y humanos, los cuales se circunscriben a una porción de territorio rural con límites espaciales muy bien 
Figura 3. Zonas de uso del suelo de Viotá

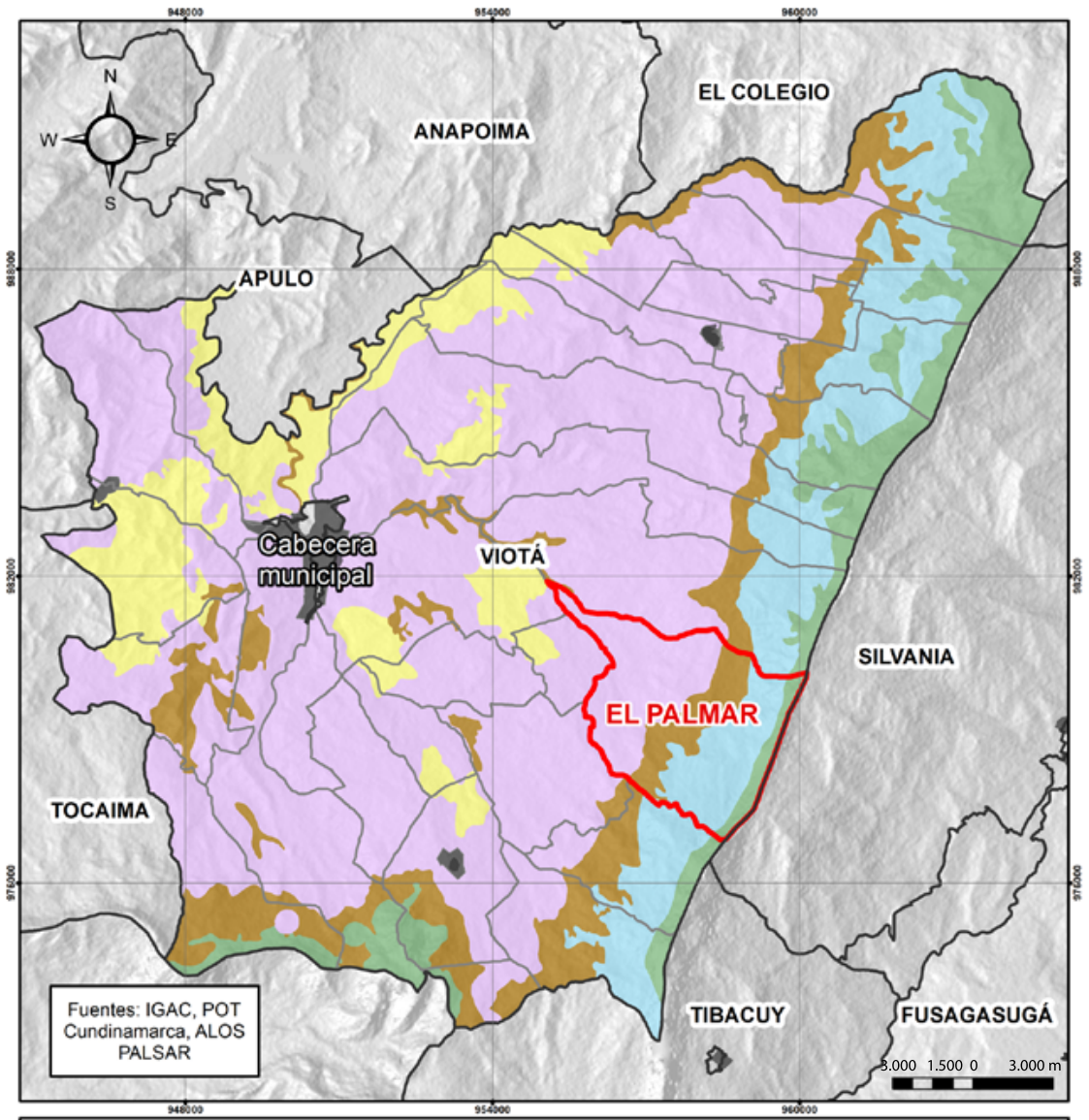

\section{ZONAS DE USO DEL SUELO DE} VIOTÁ

\section{Leyenda}

\section{Límite municipal}

Área de nacimiento de agua

Reserva forestal protectora

Zonas urbanas

Reserva forestal protectora-productora Área agropecuaria semi-mecanizada Área agropecuaria tradicional

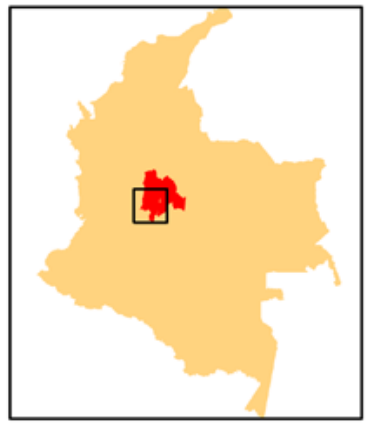

Fuente: Elaboración propia a partir de Cartografía base IGAC, ЕOT Viotá-Cundinamarca, Alos Palsar. 

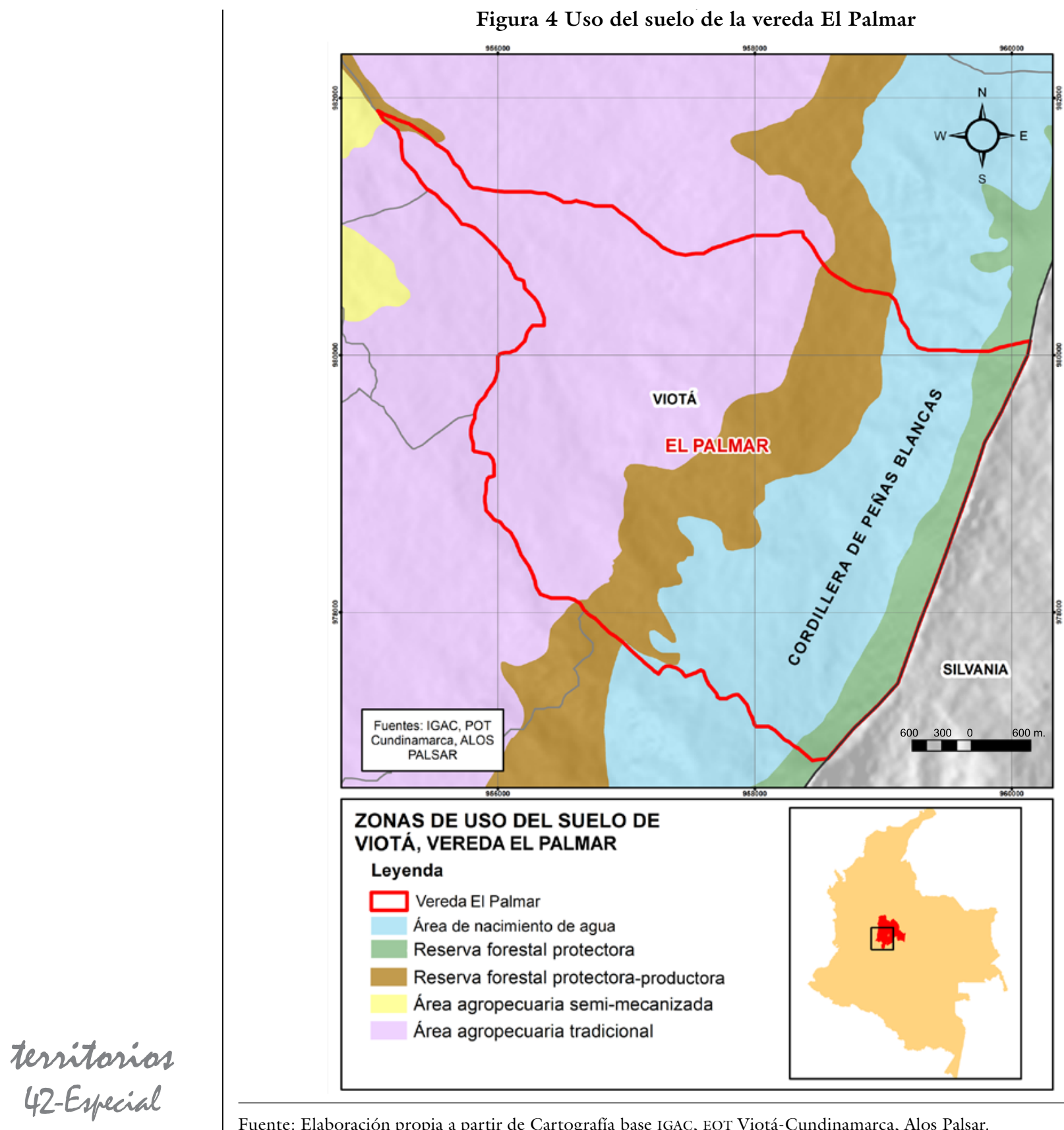

ZONAS DE USO DEL SUELO DE VIOTÁ, VEREDA EL PALMAR

Leyenda

Vereda El Palmar

Área de nacimiento de agua

Reserva forestal protectora

Reserva forestal protectora-productora

Área agropecuaria semi-mecanizada

Área agropecuaria tradicional

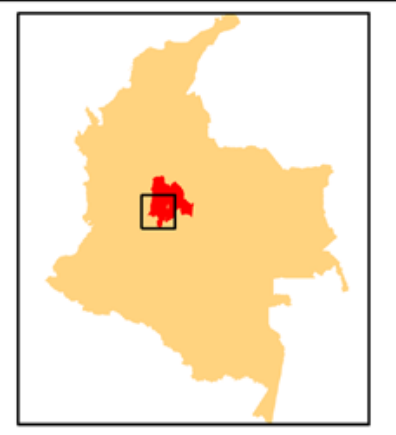

Fuente: Elaboración propia a partir de Cartografía base IGAC, EOT Viotá-Cundinamarca, Alos Palsar. 
definidos, en el que los agroecosistemas o ecosistemas cultivados son su componente principal, aunque en algunos casos pueden integrar ecosistemas silvestres y sistemas extractivos (Herrera \& Nadal, 2015). Como se puede observar en la figura 4 , los sistemas de producción de la vereda El Palmar dan cuenta de actividades actuales y usos potenciales del suelo.

Con el paso del tiempo, el establecimiento de la zonificación y las restricciones de usos del suelo cobijado por la figura de Distrito de Manejo Integral ha implicado importantes transformaciones en las relaciones de la comunidad con el territorio. Si bien la zonificación no altera el régimen de propiedad, las restricciones a la actividad agrícola, la gestión del agua y los derechos adquiridos sobre la tierra son algunos de los aspectos más problemáticos que se han presentado. De esta forma, la zona de reserva constituye uno de los conflictos territoriales que más impacto tiene en la vida de los campesinos de las veredas que se ubican dentro del área protegida. La misma área había sido objeto de disputas históricas a principios del siglo Xx, por la construcción de zonas privadas dentro de las grandes haciendas cafeteras, pero de explotación de recursos de uso común para los campesinos. Con el paso del tiempo, las concesiones de uso fueron reducidas por parte de los hacendados, lo que tornó la Cuchilla en un escenario de resistencia campesina a través de la tala, invasión y siembra clandestina (Jiménez, 1978; 1988).

\section{Disputa en torno a las figuras de ordenamiento}

En la visión del territorio que emerge del proyecto de desarrollo convencional, del cual hacen parte el desarrollo sostenible, los recursos naturales y el territorio, estos se tornan objetos de la explotación del capital, de allí que se pongan a disposición de los intereses de la explotación conservacionista, intereses distantes a los de los campesinos que habitan, viven y construyen el territorio, lo cual se ve reflejado en las políticas rurales. Leff, Argueta, Boege \& Porto-Gonçalves (2002) lo plantean de la siguiente forma:

la naturaleza ha dejado de ser un objeto del proceso de trabajo para ser codificada en términos del capital, transmutándose en una forma del capital — capital natural- (...) Es en este sentido que (...) hoy se promueve una explotación "conservacionista" de la naturaleza. La biodiversidad aparece [...] como zonas de reservas de naturaleza - territorios y hábitat de esa diversidad biológica y cultural—, que hoy están siendo valorizados por su riqueza genética, sus recursos ecoturísticos o su función como colectores de carbono. Si en épocas pasadas la razón moderno-colonial construyó en América Latina latifundios de caña de azúcar, plátano, café y algodón, el nuevo sentido de la biodiversidad para el capital está llevando a generar un nuevo tipo de latifundio, el latifundio genético (p. 478). tersitorias 42-Especial 


\section{territorias 42-Especial}

En Peñas Blancas, muchos propietarios con desconcierto han descubierto el traslapamiento de sus títulos con aquellos nuevos "latifundios genéticos". La necesidad de proteger y conservar la base natural del territorio va mucho más allá de las figuras de protección; sin embargo, como sostuvo un campesino habitante de la zona, cuando estas figuras son arbitrariamente establecidas es necesario que

los dueños de esos predios sean tenidos muy en cuenta porque de pronto en esa zona hay gente que vive solamente de ese pedazo de terreno. Sabemos que lo más lógico es que dentro de ese terreno hubiera muchos árboles y reforestación. Que no hubiera esto, que no hubiera lo otro. Pero también hay que mirar muy claramente a los dueños de esos predios (Campesino habitante de Palmar Bajo, 2015).

Si bien se trata de medidas de gran impacto en la vida productiva de los campesinos, la comunidad no ha sido adecuadamente informada; al contrario, se han venido enterando a medida que han solicitado sus respectivos certificados o títulos de propiedad. "En mi finca yo tengo todo lo que uno ha cultivado aquí siempre: café y plátano, que de eso es que vivimos nosotros, ni siquiera ganado tenemos", expresó un campesino. De igual forma, tampoco existe claridad sobre los criterios de definición y delimitación implementados por las entidades para imponer las afectaciones, pues fincas ubicadas en los 1770 m.s.n.m. aparecen sorpresivamente restringidas para el uso agrícola ( siembra de café), el cual tradicionalmente ha proveído el sustento de las familias de la subregión.

Yo mandé un derecho de petición donde les decía que, si era por motivo de zona de protección o río o reforestación, bien, ¿quién no cuida el agüita? ¿Quién no necesita el agua? Pero en ese sentido uno lo que les pide es que no nos perjudiquen con esas decisiones (Campesino habitante de Palmar Bajo, 2015).

Ante el desajuste entre la zonificación de la reserva y las actividades de sustento, uno de los habitantes afectados especula sobre la forma como se efectuó el reconocimiento del territorio:

cuando hicieron el censo forestal, lo hicieron satelitalmente, hace unos 25 años y bajaron de la pata de la cordillera 500 metros. Yo sé, porque yo estuve en esa comisión y pues claro: el avión cogió lo indebido. Pero ahí donde está mi finca no es mancha de bosque. Tengo un nacedero que todo el mundo conoce porque hace unos 30 años se sacaba el agüita en una tacita y nunca se secaba y yo mantuve el bosque anchito, bonito (Campesino habitante de Palmar Bajo, 2015).

Para los campesinos, la existencia de títulos de propiedad en la franja cuestiona en sí las políticas de ordenamiento que 
se han implementado en la región, las cuales contradictoriamente permitieron en el pasado la concesión de derechos de propiedad a los campesinos en ella, y en el presente propenden a restringir los usos agrícolas de dicho territorio:

¿Quién les vendió esas tierras a los campesinos si cuando la Caja Agraria parceló dejó una franja de reserva muy buena? Llegó el Incora [Instituto Colombiano para la Reforma Agraria] y les tituló, entonces el campesino no tiene culpa. Además, al campesino que se tomó todas esas tierras también se las titularon, entonces nosotros somos dueños ya de estas tierras (Campesino habitante de Palmar Bajo, 2015).

Vemos aquí una concepción campesina de propiedad como un derecho de uso sin restricciones, contrario a lo que ocurre, por ejemplo, en otros lugares que poseen áreas de influencia arqueológica. Para este campesino, ser dueño de la tierra es contradictorio con ser sujeto al ordenamiento territorial en la medida que el ordenamiento entra en tensión con la realidad social, económica y cultural de las poblaciones campesinas que requieren para su subsistencia que se permitan usos agropecuarios tradicionales del suelo.

La afectación en los derechos de uso asociados a los títulos de propiedad está constituyendo un obstáculo para las dinámicas de la pequeña producción campesina de estas veredas. Son dos los problemas identificados que acarrea la "restricción de las fincas”. En primer lugar, está el aspecto relacionado con la imposibilidad de acceder a créditos, como lo expresa un campesino afectado:

Nosotros tenemos que renovar de alguna manera el café y no nos alcanza por los precios. Entonces nos toca ir al banco a que nos den un crédito. Ya le digo: yo desde el 80 soy cliente del Banco Agrario y el año pasado me salió un préstamo. Esta vez me llamó el gerente porque ya me tenía aprobado el crédito, pero me dijo: "pida el certificado de libertad". ${ }^{3} \mathrm{Y}$ salió restringido (Campesino habitante de Palmar Bajo, 2015).

El segundo problema tiene que ver con la inviabilidad de venta de los predios. Si un campesino que vive de la producción agrícola empieza a tener restricciones para trabajar la tierra, bien sea porque se le prohíba cultivar o se le dificulte el acceso a los créditos, es posible que opte por vender. La anterior opción, sin embargo, es poco factible:

Va uno a vender la finca, porque ahí dice que uno puede venderla o puede arrendar, subarrendar. ¿Pero quién va a comprar una finca restringida? Lo primero que usted me pide es la escritura: "tres fanegadas y media". ${ }^{4}$ Luego me pide el certificado de libertad, de pronto puede estar embargada la finca o puede no ser mía o aparece la restricción. Entonces, ¿quién me compra? (Campesino habitante de Palmar Bajo, 2015).
${ }^{3}$ El certificado de tradición $y$ libertad es un documento público emitido por la Superintendencia de Notariado y Registro que permite conocer la situación jurídica de los bienes inmuebles.

${ }^{4}$ Una fanegada equivale a $6400 \mathrm{~m}^{2}$.

territarias 42-Especial 
Este cuestionamiento invita a pensar en la posibilidad de que gente no-campesina, a quienes no les afecta la restricción de los títulos, ingresen al territorio. La venta de terrenos a agentes foráneos advierte serias implicaciones sobre los modos de vida campesinos y, particularmente, frente a la gestión del agua:

Aquí va a venir gente a ofrecer buena plata por las fincas, pero para convertirlas en fincas de veraneo, no fincas para cultivar café ni pasto ni plátano, sino veraneo. Por allá ya están comprando y están construyendo. Cada persona que llegue y compre un lotecito adquiere un derecho sobre el agua, se convierte en un consumidor y en un contaminador porque trae basura. Entonces hay una orientación que está saliendo del mismo campesinado: no vendamos las fincas (Campesino habitante de Palmar Bajo, 2015).

La descampesinización del territorio se entiende como el conjunto de prácticas en contra del proyecto de vida campesina, esto es, como un proceso dirigido a dejar al campesinado al margen del ámbito de lo social y lo público mediante actos que producen daño a su humanidad y labor (Observatorio Internacional sobre el proceso de DDR y la aplicación de la Ley de Justicia y Paz, 2012). De esta forma, la descampesinización del territorio a partir de la venta de predios bien sea al Estado o a agentes externos es identificada por la comunidad como una amenaza.

\section{La propiedad campesina como instrumento de protección del territorio}

El tema de la venta de los terrenos incluidos en la zona de reserva genera polémica entre los habitantes. De un lado, el único comprador viable para algunos sería el Estado; sin embargo, los campesinos reconocen que el tema de las franjas protegidas tiene una escala mayor a la de la subregión y en este sentido:

el Estado ahí manda decir: "nunca vamos a comprar porque no hay plata". Es que no es solamente un área, nosotros tenemos el mapa y está restringido todo lo que es Soacha, Madrid, Faca, Fusa. Todo eso está restringido, desde Villa Pinzón en los límites con Boyacá hasta los límites del río Sumapaz con el Tolima. Entonces lógico, para ellos es mucha gente. Pero yo miro y es un atropello (Campesino habitante de Palmar Bajo, 2015).

No obstante, frente a la imposibilidad o desinterés de la nación por adquirir los terrenos a escala regional, surge el temor campesino a la expropiación:

Llega el momento que, así como usted no puede tumbar un árbol, que tendrá que pasar pronto, también va a llegar el momento que dicen que está por encima el bien supremo del bien personal y el bien supremo es el agua. Si queremos garantizar agua entonces vamos a que esta franja de

Paula Kamila Guerrero García 
tierra sea únicamente para reforestarla y no más. Entonces ¿qué será mejor, que les compren o que los expropien? (Campesino habitante de Palmar Bajo, 2015).

En contraposición a la propuesta de compra de tierras en la zona de reserva forestal, surge una exigencia por el reconocimiento de la ocupación campesina en tales áreas y, especialmente, de sus derechos adquiridos:

La idea de nosotros no es decirle al campesino que tiene que vender. ¡No señor! Es que el Estado tiene que reconocer que el campesino duró muchos años ahí y que tiene su posesión y esa posesión vale porque para eso es. Tenemos que mirar en esa zona de reserva qué va a pasar con la gente y eso no es de Bajo y Alto Palmar, es la zona desde Mesitas del Colegio hasta Tibacuy. ¿Cuántos finqueros estarían en ese problema? (Campesina habitante de Palmar Bajo, 2015).

Esta idea de los campesinos nos sugiere la necesidad de generar nuevos esquemas o figuras diferentes a la compra o expropiación de los predios en las zonas de reserva. Además, el precio de compra ofrecido por el Estado en muchas ocasiones puede ser inferior al necesario por parte del campesino para adquirir otra finca, lo cual podría fomentar, entre otras cosas, los procesos de microparcelación que se vienen intensificando en el municipio desde la repartición de las haciendas cafeteras en el siglo XIX:

Vendemos, pero de pronto no nos van a dar lo que vale lo de nosotros. Entonces vamos y le decimos al vecino: "véndame una fanegada", de pronto con lo que me dan arriba me alcanza para comprarle la mitad de fanegada a ellos (Campesino habitante de Palmar Bajo, 2015).

La microparcelación en Viotá es un importante reto para el ordenamiento territorial pues intensifica la explotación del suelo y genera procesos irreparables de degradación de este.

\section{Del acaparamiento verde al despojo campesino}

Entre los habitantes existen cuestionamientos en torno a las ambivalencias en el actuar de las diferentes instituciones gubernamentales frente a las políticas del sector rural, las cuales sugieren que la situación puede estar encubriendo prácticas de despojo campesino:

A nosotros aquí nos cobija el programa [estatal] Familias en su Tierra. Cuando nosotros fuimos a unos cursos en Liberia, lo primero que nos dijeron fue que la gobernación nos iba a ayudar para que nosotros nos aferráramos a nuestras tierras. Y nos han dado bastantes ayudas. Pero entonces yo me pregunto: Si esto lo hizo el gobierno con miras a que nosotros territorias 42-Especial 
${ }^{5}$ Máxima autoridad ambiental en la jurisdicción regional. Ejecuta politicas, planes, programas y proyectos ambientales.

\section{territarias 42-Especial}

no seamos desposeídos de las tierras o las abandonemos y busquemos las ciudades, ¿entonces por qué corporaciones como la Corporación Autónoma Regional (CAR) ${ }^{5}$ vienen a hacernos esto a nosotros? Yo a veces pienso que el gobierno central no sabe estas cosas, y que habría que hacérselas saber directamente. Nosotros estamos padeciendo estos conflictos. ¿Por qué ellos nos están ayudando a que nosotros no nos movamos de nuestras tierras y la CAR viene a desposeernos? ¿Qué pasa ahí? (Campesina habitante de Palmar Bajo, 2015).

En efecto, las prácticas de la conservación muy frecuentemente implican el destierro de las personas de los lugares tradicionalmente habitados. El fenómeno denominado acaparamiento verde - green grabbing - (Vidal, 2008) se entiende como una práctica de apropiación de territorios y recursos con fines ambientales. El término apropiación hace referencia a la transferencia de la propiedad, los derechos de uso y control sobre recursos que antes eran propiedad pública o privada (Fairhead et al., 2012). Estos procesos “verdes" de acumulación y despojo se enmarcan en el proyecto neoliberal de desarrollo, en el entendido que las valoraciones neoliberales de la naturaleza aportan nuevas espacializaciones del territorio y nuevos potenciales de desigualdad con frecuencia desarticulados a su configuración territorial y a las prácticas locales (Fairhead et al., 2012, p. 244). Esta problemática del destierro ha sido abordada para casos de comunidades indígenas en Colombia que han sido desplazadas de sus territorios acuñando la categoría de refugiados de la conservación (Dowie, 2009).

Los discursos que sustentan las prácticas de apropiación del territorio y de sus recursos construyen y representan a las $\mathrm{co}^{-}$ munidades locales como ambientalmente destructivas, atrasadas y desordenadas, lo cual legitima la necesidad de intervenirlas para realizar su ajuste a las visiones del "desarrollo sostenible" (Fairhead et al., 2012). El concepto de acaparamiento verde tiene la capacidad de iluminar una serie de aspectos relevantes en la problemática de la zona de reserva que deberán ser abordados por futuras investigaciones que se concentren en dicho aspecto. $\mathrm{Si}$ bien en Viotá aún no se han presentado casos de desplazamiento a causa de la reserva, de acuerdo con la reflexión presentada párrafos atrás, los campesinos se sienten potencialmente amenazados de ser despojados y de convertirse en refugiados de la conservación por las medidas institucionales en torno al área protegida.

\section{La autonomía territorial: una propuesta emergente de desarrollo}

Algunos planteamientos con respecto a la venta de predios al Estado sugieren suspicacia frente a las decisiones que se tomen frente al manejo y al futuro del territorio:

Supongamos que se diera [la venta] en esta zona, a sabiendas de que en el mapa

Paula Kamila Guerrero García 
de petróleos la reserva más grande de hidrocarburos está debajo de estas cordilleras del Sumapaz. De pronto al pasar las tierras al Estado, como ya tienen el poder pueden venir a explotar ese petróleo. El Estado puede explotarlo, como ya pasa. Pero entonces nos van a perjudicar a nosotros, porque si hay petróleo no habrá agua. Entonces ese es el miedo que también hay del pueblo. Nosotros mandamos sobre una capita muy delgadita que es donde trabajamos y producimos, de ahí para abajo en la riqueza y el subsuelo manda el Estado (Campesino habitante de Palmar Bajo, 2015).

Más allá de la veracidad de la información con respecto a la existencia de reservas de hidrocarburos, este planteamiento trae implícita la idea de que el Estado no sería el gestor ideal del territorio, especialmente uno representado en el imaginario campesino como defensor de intereses extractivos por encima de los intereses de las comunidades. Lo anterior se conecta con ideas nacientes de gestión propia o campesina del territorio, inspiradas en procesos de autonomía territorial de otras zonas del país.

Haciendo gala de su pasado organizativo y de su capacidad para generar movilización social, algunos campesinos viotunos proponen fortalecer un movimiento que reivindique su derecho a vivir en la zona de reserva en defensa del territorio y los recursos:
¿Cómo debemos hacer nosotros para defender el agua, para defender la vida, para defender el territorio? Uniéndonos, organizándonos toda esta franja, así estemos por debajo de los metros que dice ahí. Inclusive la lucha debe de ser de todos los viotunos, de todos por la defensa del agua, tanto los que estamos acá, los que tan abajo y los que están más abajo aún. Lo que tiene que crearse es una asociación de todos los campesinos de esta franja para defender todos unidos el derecho a seguir viviendo en esa franja, en nuestras fincas. Ahora cuando se habla de que el Estado compre, que el Estado compre, pero no para que el campesino se vaya, sino para que el campesino se quede aquí, cuidando esto como guardabosques. Nosotros tenemos que defender el agua y queremos que haya un Estado en Colombia que defienda eso (Campesino habitante de Palmar Bajo, 2015).

En relación con lo anterior y la idea emergente de autonomía territorial, algunos campesinos traen a colación la figura organizativa de las Zonas de Reserva Campesina (ZRC), por ser la más similar, en términos de protección territorial, a la que poseen los resguardos indígenas, aunque estos últimos son una institución legal y sociopolítica de carácter especial. Las ZRC son un mecanismo encaminado a eliminar y prevenir la inequitativa concentración de la propiedad o su fraccionamiento antieconómico, y regular la ocupación territarios 42-Especial 
y aprovechamiento de las tierras baldías de la nación. Son áreas geográficamanete delimitadas que tienen en cuenta las características ambientales, agroecológicas y socioeconómicas regionales para el ordenamiento territorial, social y cultural de la propiedad, para la estabilización y consolidación de la economía campesina (artículo 80 de la Ley 160 de 1994; Acuerdo 024 de 1996). Al parecer, el tema viene generando reflexión desde otras comunidades campesinas frente a la necesidad de proteger sus territorios:

Hay una figura que la están peleando por ejemplo en el Cauca que sí les da poder a los campesinos para mandar en ese territorio y no dejar explotar nada, porque es una figura que la ley misma hace respetar y por eso ya hay unas peleas en otros departamentos para que el Estado le respete a los campesinos. Esa es la figura de las Zonas de Reserva Campesinas (Campesina habitante de Palmar Bajo, 2015).

Aunque el principal conflicto que se analizó es aquel entre la comunidad y el Estado, hay que resaltar que este también deriva en tensiones entre los mismos campesinos. Esta propuesta en particular causa polémica entre aquellos que se aferran a mantener los derechos de propiedad privada sobre su tierra y, particularmente, quienes desean tener la posibilidad de vender su tierra, si así lo desean. En términos generales, los campesinos son conscientes de que tienen parte de responsabilidad en el deterioro de los ecosistemas de la parte alta del municipio a través de sus prácticas de siembra, manejo de desechos y deforestación. Sin embargo, en el presente reconocen la necesidad inminente de proteger y de conservar para mantener la funcionalidad del ecosistema de la Cordillera de Peñas Blancas. Saben que el suministro de agua depende del manejo que reciba esta franja y cada día de verano cuando salen a "cazar agua" en las enmarañadas mangueras de sus veredas, viven en carne propia las consecuencias del manejo que ha recibido el recurso hídrico en la región.

La problemática en torno al área protegida ha desencadenado reflexiones para los campesinos de las veredas afectadas, quienes han empezado a visualizar salidas frente a la necesidad de solucionar este conflicto. Los argumentos de los campesinos apuntan no solo a permanecer en el territorio, lo que denota su arraigo a él, sino a ejercer la defensa activa del mismo bajo el entendido de que el modo de vida campesino no contradice la conservación de los recursos.

La importancia de la zona de reserva no está en cuestión; mas, es fundamental encontrar salidas concertadas a los conflictos que suponen las rígidas figuras del ordenamiento institucional orientadas a la conservación y protección de la biodiversidad:

Estamos de acuerdo que sí, que hay que proteger la franja y hay que proteger la

Paula Kamila Guerrero García 
reserva, hay que reforestar. Pero tampoco estamos de acuerdo que a los campesinos nos saquen así, casi como desplazarnos. No es la solución. ¿Qué es lo que hay que hacer aquí? Hay que comenzar a hablar con la gente para hacer claridad y luego mirar con la CAR, el Ministerio del Medio Ambiente y el Estado para que logremos llegar a unos acuerdos, a unos convenios que nos permitan preservar los recursos sin necesidad de expropiar o de desplazar al campesino (Campesino habitante de Palmar Bajo, 2015).

La necesidad de conservación, estudio y aprovechamiento de la biodiversidad en todos los países del mundo ha configurado una serie de discursos y representaciones que construyen un estigma sobre las comunidades que habitan aquellas áreas consideradas ecológicamente estratégicas, sobre quienes recae la responsabilidad de su cuidado, como señala Ruíz (2003). Lo anterior es especialmente cierto para las representaciones que persisten en las visiones estatales que estigmatizan a los campesinos como destructores del entorno, al tiempo que las comunidades indígenas y afrodescendientes son representadas como custodios de sus terrenos ancestrales. Esta construcción académica que vincula la etnicidad con la territorialidad (Restrepo, 2013) logró permear las visiones Estatales, principalmente a partir de la Constitución Política de 1991. En ese sentido, una de las soluciones a este conflicto se relaciona con la necesidad de que el Estado colombiano transforme su visión de los campesinos hacia una que los conciba como sujetos ambientales, esto es, como comunidades a las que les interesa proteger sus territorios tanto como a indígenas y afrodescendientes.

En el siglo pasado, las luchas de los campesinos viotunos fueron de corte agrario en relación con la propiedad de la tierra. En el presente, la recomposición de los movimientos campesinos de escala subregional se está dando en torno a conflictos territoriales que surgen a partir de la proscripción del uso del suelo por parte de las figuras institucionales de ordenamiento del territorio, las cuales limitan las posibilidades de autonomía que demandan los campesinos para seguir siendo campesinos. El reclamo de los habitantes de la subregión de Peñas Blancas por consolidar proyectos de autonomía en la gestión de los recursos tanto en la delimitación de las áreas, como en la explotación razonable de recursos forestales y productivos se fundamenta en su autorreconocimiento como población rural con capacidades y conocimiento para participar en decisiones de política pública sobre ordenamiento territorial en el municipio (figura 5 ). Lo anterior se vincula con las ideas emergentes que propenden por la consolidación de una ZRC, lo cual implicaría un proceso organizativo largo y complejo que, a juzgar por la historia del municipio, los habitantes de Viotá estarían en capacidad de lograr. Todo lo anterior confluye hacia lo que podría territarios 42-Especial 
interpretarse como una propuesta emergente de desarrollo campesino subregional orientada hacia la autonomía territorial como ejercicio de gobierno que realizan las comunidades sobre el espacio físico en el cual existen como colectivo y como cultura, sin intervención del Estado o de otros agentes.

Figura 5. Caminata "Por la defensa del futuro". Peñas Blancas al fondo

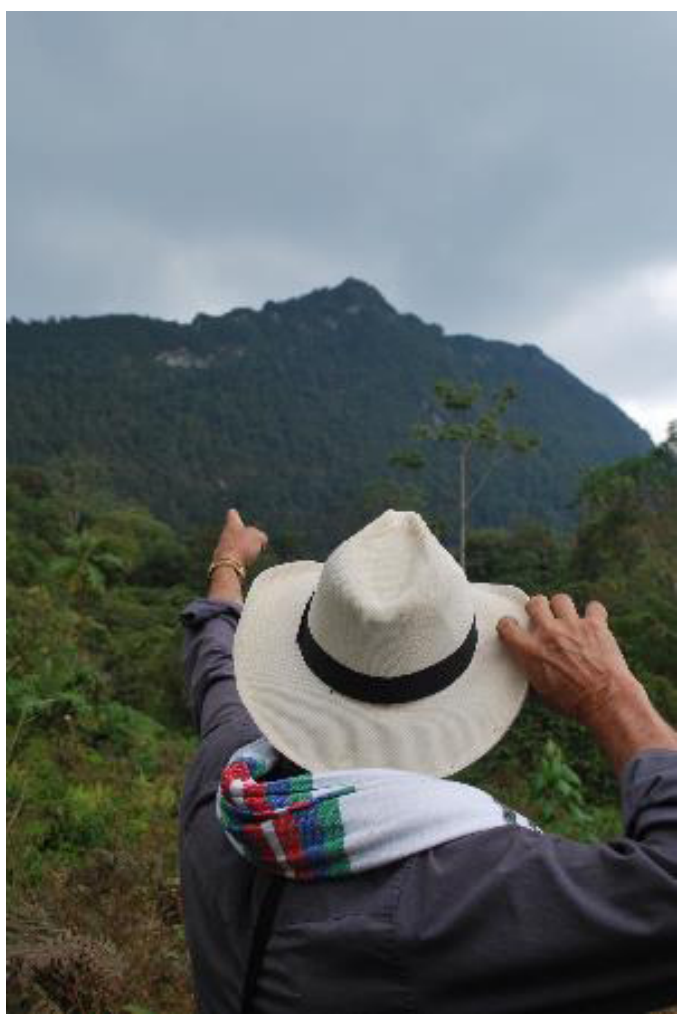

Fuente: tomada por la autora.

\section{Un ordenamiento por la defensa del futuro campesino}

Bajo los preceptos del desarrollo sostenible, las políticas ambientales del municipio parecen estar dándole la cara a la cordillera, pero la espalda a la comunidad. La proliferación de áreas naturales protegidas en espacios rurales evoca una antigua dicotomía entre conservación y desarrollo, pero específicamente plantea la necesidad de armonizar el ordenamiento del territorio, la planificación ambiental y el desarrollo rural (Troitiño, 1995). Las regulaciones ambientales que se establecen en zonas rurales, más allá de condicionar las formas de producción campesina, transforman las formas como los campesinos se han relacionado con el territorio por generaciones, creándolo y apropiándolo.

Esta experiencia de investigación en Viotá evidencia algunos de los múltiples desafíos del desarrollo rural en un país como Colombia, donde el tema agrario ha vuelto a estar en boga a partir del proceso de implementación de los acuerdos firmados entre el Gobierno y las FARC en el 2016. Las reflexiones que se derivan de estas páginas se presentarán a continuación con relación a tres campos de análisis: desarrollo, ordenamiento territorial y desarrollo rural de Viotá.

En primer lugar, los desajustes entre los que hemos llamado aquí modelos institucionales y visiones locales de ordenamiento expresan las tensiones entre el modelo de desarrollo basado en el 
crecimiento económico y en el libre mercado, orientador de las políticas rurales, y el sentido y significado que los habitantes confieren a los espacios locales (Cruz et al., 2011), lo que resulta en disputas que transforman conflictivamente las relaciones que se dan entre las instituciones y los actores por el territorio. A este se le atribuyen funciones que se derivan de las lógicas imperantes en los modelos de desarrollo, frecuentemente privilegiando la dimensión productiva y la competitividad e ignorando las lógicas y funciones que los habitantes construyen en él.

El desarrollo sostenible dentro del cual se enmarcan las políticas de ordenamiento del territorio rural en el presente ha de entenderse en el marco del proyecto neoliberal de desarrollo, el cual es "necesariamente un proyecto ambiental con el mundo no humano como parte fundamental de su razón de ser" (Fairhead et al., 2012: 240). La revisión de documentos institucionales permite evidenciar la forma como aquel modelo imperante de desarrollo al servicio del capital y del mercado reconfigura los territorios rurales a través del uso y la producción del espacio geográfico desde la racionalidad instrumental. En este sentido, el ordenamiento de los territorios se enlaza con el modelo de desarrollo, bien sea para reproducirlo o para interpelarlo. Con respecto al ordenamiento territorial institucional de Viotá, se evidenció que da respuesta a directrices de orden regional y nacional. No obstante, no logra armonizar dichas escalas con lo local, que presenta un contexto rural, agrícola, donde surgen conflictos territoriales al proscribir el uso tradicional del suelo. En esta medida, es fundamental que en el ordenamiento de los territorios locales los criterios técnicos de mayor escala dialoguen con criterios territoriales tales como la historia del poblamiento, la memoria en torno al territorio y la transformación histórica de las prácticas productivas que se dan en él.

En segundo lugar, en lo que se refiere al ordenamiento territorial institucional de Viotá, este se enmarca en los preceptos del desarrollo sostenible con un importante énfasis en la conservación y protección de los recursos naturales. La preocupación mayúscula por los recursos del municipio coincide con la propuesta de desarrollo agrario con base en el turismo, evidenciada en los documentos de política, lo que podría indicar que el interés allí no es la supervivencia de las formas de vida campesina, sino una nueva forma de explotación "conservacionista" de la naturaleza (Leff et al., 2002). En un municipio que tiene importantes necesidades aún no resueltas y cuya población proyecta su identidad campesina hacia el futuro, las políticas de ordenamiento institucional no aparecen concertadas ni validadas con los intereses y visiones de la población campesina. Se observa, como en muchos otros municipios, que el mercado de la tierra está paulatinamente favoreciendo vocaciones no campesinas como usos turísticos y recreativos, que entran territarios 42-Especial 


\section{territorias} 42-Especial en tensión con los intereses y necesidades del pequeño productor, encareciendo la vida local y alterando la disponibilidad de algunos recursos, espacialmente del agua.

En la actualidad, el conflicto territorial generado por el establecimiento del área protegida ha atizado la capacidad organizativa de los campesinos de la subregión. Hoy, sin embargo, su discurso es diferente pues no es una parcela lo que se defiende: es el territorio. Las reflexiones en torno a la necesidad de proteger y conservar la Cuchilla de Peñas Blancas para mantener su forma de vida campesina a través del cultivo de la tierra ponen sobre la mesa diferentes tipos de demandas, como la de inclusión de la población en la toma de decisiones frente al manejo del territorio, la de reconocer su derecho de propiedad y permanencia en su territorio y la de autonomía en la gestión de la zona de reserva que sea compatible con la vocación campesina del mismo. Para lograr lo anterior, es necesario admitir que el conocimiento del territorio es fundamental para ordenarlo; además, el reconocimiento y validación de los sujetos que lo habitan es tan vital como necesario para dicho proceso.

Los deseos expresados por los campesinos de la subregión afectada por estas figuras de ordenamiento configuran lo que hemos nombrado una propuesta emergente de desarrollo campesino para enfrentar la globalización neoliberal. Esto se articula con el planteamiento de Barkin $(2001 ; 2012)$ según el cual los principios de autonomía, autosuficiencia y diversificación productiva (Barkin, 2001 , p. 33) son una vía para superar el paradigma neoliberal en el campo. Este autor vislumbra una nueva ruralidad comunitaria a partir de una base productiva diversificada, el uso creativo de los recursos y la participación locales en la planeación e implementación de decisiones. La subregión de Peñas Blancas en Viotá constituye un territorio propicio para emprender un proceso alternativo de este tipo, a través de la comprensión del dinamismo del territorio y una construcción del desarrollo local desde los sujetos sociales (Cruz et al., 2011).

En este sentido, la comprensión de las dinámicas históricas de los territorios, sus usos actuales y las múltiples maneras de apropiarlo por parte de los campesinos se propone como una de las vías para prevenir y abordar los conflictos territoriales que surgen de la implementación de políticas de un ordenamiento institucional cuyas funciones, zonificaciones, figuras y orientaciones entran en disputa con las visiones que tienen del territorio quienes lo habitan. Frente a este aspecto, la etnografía como hilo conductor de la investigación logró develar múltiples significados y evidenciar prácticas fundamentales para un ejercicio de ordenamiento coherente con las comunidades. Por su lado, Viotá cuenta con un importante camino recorrido en términos organizativos de la comunidad y el compromiso por proteger su territorio, 
con una perspectiva agrícola y hacia un ordenamiento por la defensa del futuro campesino.

\section{Referencias}

Alcaldía Municipal de Viotá. (2001). Esquema de Ordenamiento Territorial del Municipio de Viotá. “Ordenamiento y desarrollo sostenible: Consideraciones para un futuro en paz". Componente general. Viotá, Cundinamarca: Alcaldía Municipal.

Barkin, D. (2001). La nueva ruralidad y la globalización. En E. Pérez \& A. Farah (Eds.), La nueva ruralidad en América Latina. Maestría en desarrollo rural 20 años (Vol. 2, pp. 21-40). Bogotá: Pontificia Universidad Javeriana.

Barkin, D. (2012). Superando el paradigma neoliberal: desarrollo popular sustentable. Cuadernos de Desarrollo Rural, (43).

Cruz, R., Cruz, J., Meza, A., Olivares, M., \& Palacios, E. (2011). Pensar al territorio desde la perspectiva del desarrollo rural. En C. Cortez, Á. Gama, A. Gómez, M. Pérez, \& C. Rodrígez (Eds.), El desarrollo rural en México $y$ Colombia: problemas comunes y respuestas emergentes de los actores, (pp. 93-118). México, D. F: Universidad Autónoma Metropolitana, Unidad Xochimilco - Pontificia Universidad Javeriana.

Dowie, M. (2009). Conservation refugees: the hundred-year conflict between global conservation and native peoples. Cambridge: MIT Press.

Fairhead, J., Leach, M., \& Scoones, I. (2012). Green Grabbing: a new appropriation of nature? Journal of Peasant Studies, 39(2), 237-261. https://doi. org/10.1080/03066150.2012.671 770

Herrera, J., \& Nadal, D. (2015). Informe final del componente ambiental y cartográfico. La cartografía social de Viotá. Proyecto "Viotá, poniendo los cimientos para la construcción de Paz". Informe inédito. Bogotá: Pontificia Universidad Javeriana.

Jiménez, M. (1978). Viotá: the history of a Colombian coffee municipality. Harvard: Harvard University Press.

Jiménez, M. (1988). Traveling far in grandfather's car: The life-cycle of central Colombian coffee estates: The case of Viotá, Cundinamarca (1900-1930). Princeton: Princeton University Press. Leff, E., Argueta, A., Boege, E., \& PortoGonçalves, C. (2002). Más allá del desarrollo sostenible. La construcción de una racionalidad ambiental para la sustentabilidad: Una visión desde América Latina. En E. Leff (Ed.) La transición hacia el desarrollo sustentable: perspectivas de América Latina y el Caribe, (pp. 477-576). México, DF: Secretaría de Medio Ambiente y Recursos Naturales - Universidad Autónoma Metropolitana, Unidad Xochimilco, PNUMA. territarias 42-Especial 
Observatorio Internacional sobre el proceso de DDR y la aplicación de la Ley de Justicia y Paz. (2012). Quinto informe. Madrid: CITpax.

Restrepo, E. (2013). Etnización de la negridad: la invención de las "comunidades negras” como grupo étnico en Colombia. Popayán, Colombia: Editorial Universidad del Cauca.

Ruíz, D. (2003). Campesinos entre la selva, invasores de reservas. Tabula Rasa, (1), 183-210.
Troitiño, M. A. (1995). Espacios naturales protegidos y desarrollo rural: una relación territorial. Boletín de la Asociación de Geógrafos Españoles, (20), 23-37.

Vidal, J. (febrero 13, 2008). The great green land grab. The Guardian. Recuperado de https://www.theguardian. com/environment/2008/feb/13/ conservation 